\title{
Estudio inmunohistoquímico en un caso de colocistoplastia operado hace 51 años
}

\author{
Arango Toro O, Álvarez-Vijande R*. \\ Servicio de Urología. Hospital del Mar. Barcelona. *Servicio de Urología. Hospital Clínic i Provincial de Barcelona.
}

Actas Urol Esp. 2008;32(3):363-366

Sr. Director:

Por lo inusual, queremos dar a conocer la evolución, del que posiblemente sea uno de los segmentos de intestino que más tiempo ha estado en contacto con la orina en todo el mundo, el cual ha sido seguido rigurosamente durante 51 años por el mismo equipo médico que lo operó, habiéndose podido comprobar la excelente adaptación del intestino a su nueva función de reservorio urinario, así como la ausencia de complicaciones o de cambios sugestivos de malignización.

Se trata de un paciente de 79 años, al que en el año 1956 el Prof. José $M^{\text {a }}$ Gil-Vernet le realizó en el Hospital Clínico Universitario de Barcelona una nefrectomía izquierda por un riñón mastic y una colocistoplastia de aumento por una pequeña vejiga tuberculosa. Para la cistoplastia utilizó un segmento de $15 \mathrm{~cm}$. de longitud del colon sigmoides parcialmente destubulizado, el cual fue anastomosado en latero-lateral al trígono vesical previa cistectomía subtotal debido a la sustitución del detrusor por tejido fibroso retráctil. Desde el principio, el paciente presentó micciones normales y siempre ha sido totalmente continente, tanto de día como de noche ${ }^{1-3}$. Actualmente presenta una frecuencia miccional de 4 horas y la creatinina plasmática es de 1,3 mg/dl. En la UIV y el TAC se aprecia normalidad morfofuncional del riñón derecho, vejiga de capacidad aumentada y residuo postmiccional moderado (Fig. 1). En la cistoscopia-biopsia tanto la mucosa del segmento intestinal como la del remanente trigonal presentaban un aspecto normal y no se objetivaron lesiones tumorales ni litiasis, siendo difícil distinguir el punto de unión entre el intestino y el trígono. La capacidad vesical ha ido aumentando paulatinamente, de tal manera que si inicialmente era de tan sólo 200 cc, a los 10 años era de 300 cc, a los 30 años de 500 cc y a los 51 años es de $700 \mathrm{cc}$, siendo atribuible este aumento al desarrollo de HBP en los últimos años.
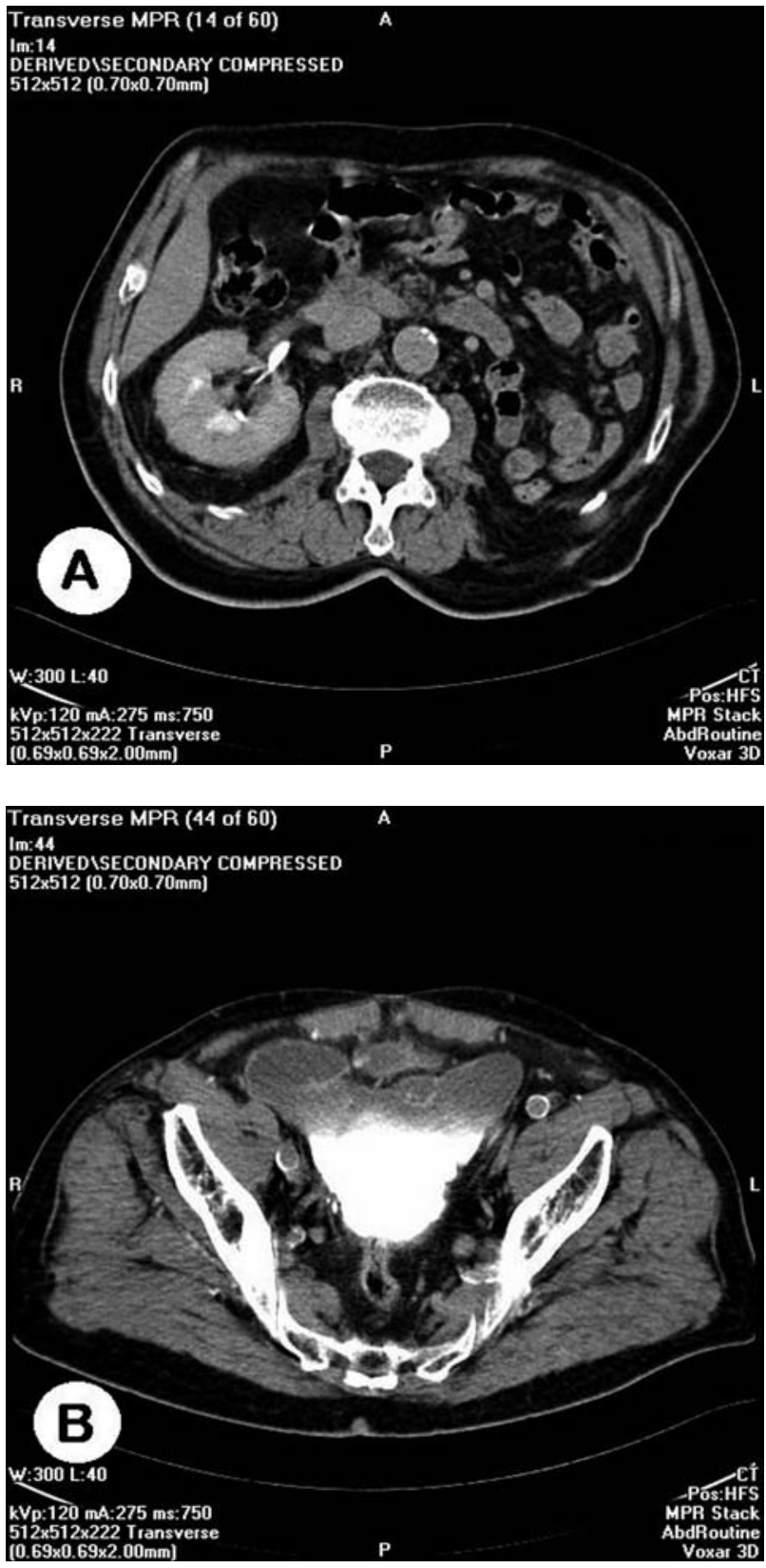

FIGURA 1. TAC. A) Riñón derecho y cavidades renales de aspecto normal. B) Cistoplastia de aumento con colon sigmoides. 
El estudio anatomopatológico de las biopsias del segmento intestinal demostraron leve componente inflamatorio crónico en la lámina propia, sin observarse lesiones de tipo preneoplásico. Igualmente las biopsias del remanente cervico-trigonal y de la unión vésico-intestinal demostraron urotelio papilomatoso con exudado leucocitario a través del epitelio, pero sin cambios premalignos. Estos hallazgos son superponibles a los de las biopsias previas realizadas a los 20 y 30 años de seguimiento, sin que sea apreciable actualmente ningún cambio histológico que sugieran transformación maligna del intestino en contacto con la orina (Fig. 2).

La inmunohistoquímica realizada en las biopsias de urotelio, intestino y unión vesico-intestinal con anticuerpos para antígeno de proliferación Ki-67, anticuerpo para proteína p53 y expresión de citoqueratina 20, fueron compatibles con cambios reactivos y descartaron cambios de malignización después de
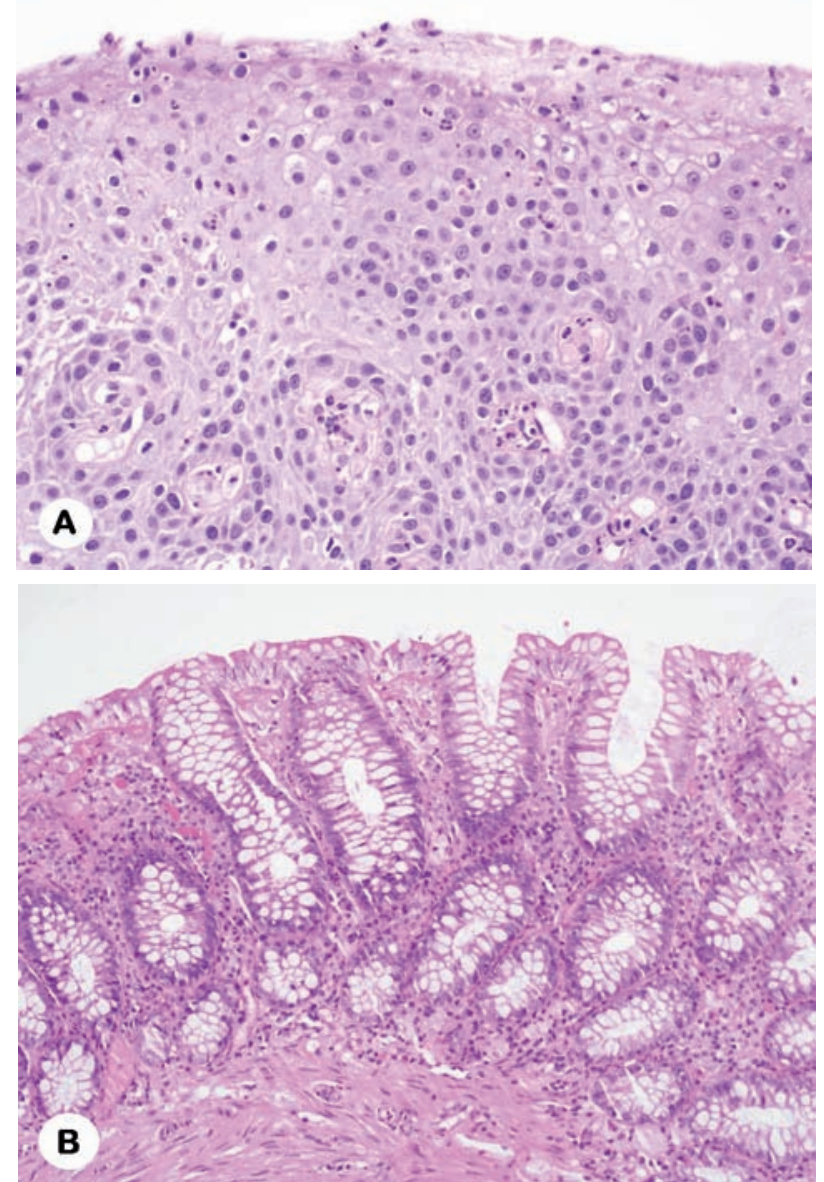

FIGURA 2 A) Biopsia del remanente vesical con cambios inflamatorios crónicos HE 400X. B) Mucosa del segmento intestinal de aspecto normal HE 400X. estar el intestino en contacto con la orina durante 51 años (Fig. 3). Sin embargo, otros autores han demostrado cambios premalignos después de 6 a 10 años de seguimiento mediante técnicas de histología convencional e inmunohistoquímica con diversos marcadores de proliferación celular ${ }^{4}$. Más recientemente, Ivil y cols, 2006 encontraron por FISH, que con el tiempo se produce inestabilidad genética en forma de aberraciones cromosómicas numéricas en el intestino en contacto con la orina, especialmente en la zona de la anastomosis entre la vejiga y el intestino $^{5}$.

Diversos segmentos intestinales han sido utilizados para las plastias de aumento o de sustitución vesical, y cada uno de ellos tiene sus ventajas y sus inconvenientes, sin que se haya demostrado una clara ventaja con ninguno de ellos, ya que con todos se puede confeccionar un reservorio vesical que cumpla con las tres premisas principales: 1- que almacene eficazmente la orina a baja presión, 2- que proteja el tracto urinario superior y 3- que permita micciones voluntarias y confortables que le den al paciente una buena calidad de vida. No obstante, con la utilización del intestino dentro del aparato urinario se han descrito diversas complicaciones a largo plazo, tales como trastornos metabólicos, litiasis, infección crónica, ruptura espontánea y neoplasias, de las cuales nuestro paciente no ha presentado ninguna de ellas en 51 años de seguimiento.

El desarrollo de tumores en estos pacientes es una realidad, aunque es posible que el riesgo de malignización se haya exagerado. No se conoce a ciencia cierta la etiología de los tumores que se desarrollan en una cistoplastia de aumento, pero muy posiblemente sea multifactorial. Entre otros, se han relacionado con niveles elevados de nitrosaminas, que al activarse metabólicamente producen sustancias alquilantes que forman enlaces covalentes con el DNA de las células en proliferación, que no dan tiempo a que ésta reparare su DNA y se produce la iniciación del tumor ${ }^{6}$.

Los tumores de estos pacientes pueden tener su origen tanto en el epitelio intestinal como en el remanente urotelial, aunque la mayoría de publicaciones coinciden en que el sitio más frecuente de presentación es a nivel de la línea de unión entre el intestino grueso y el remanente vesical, dado que el "conflicto" entre ambos epitelios aumenta la proliferación celular. El tipo de tumor 

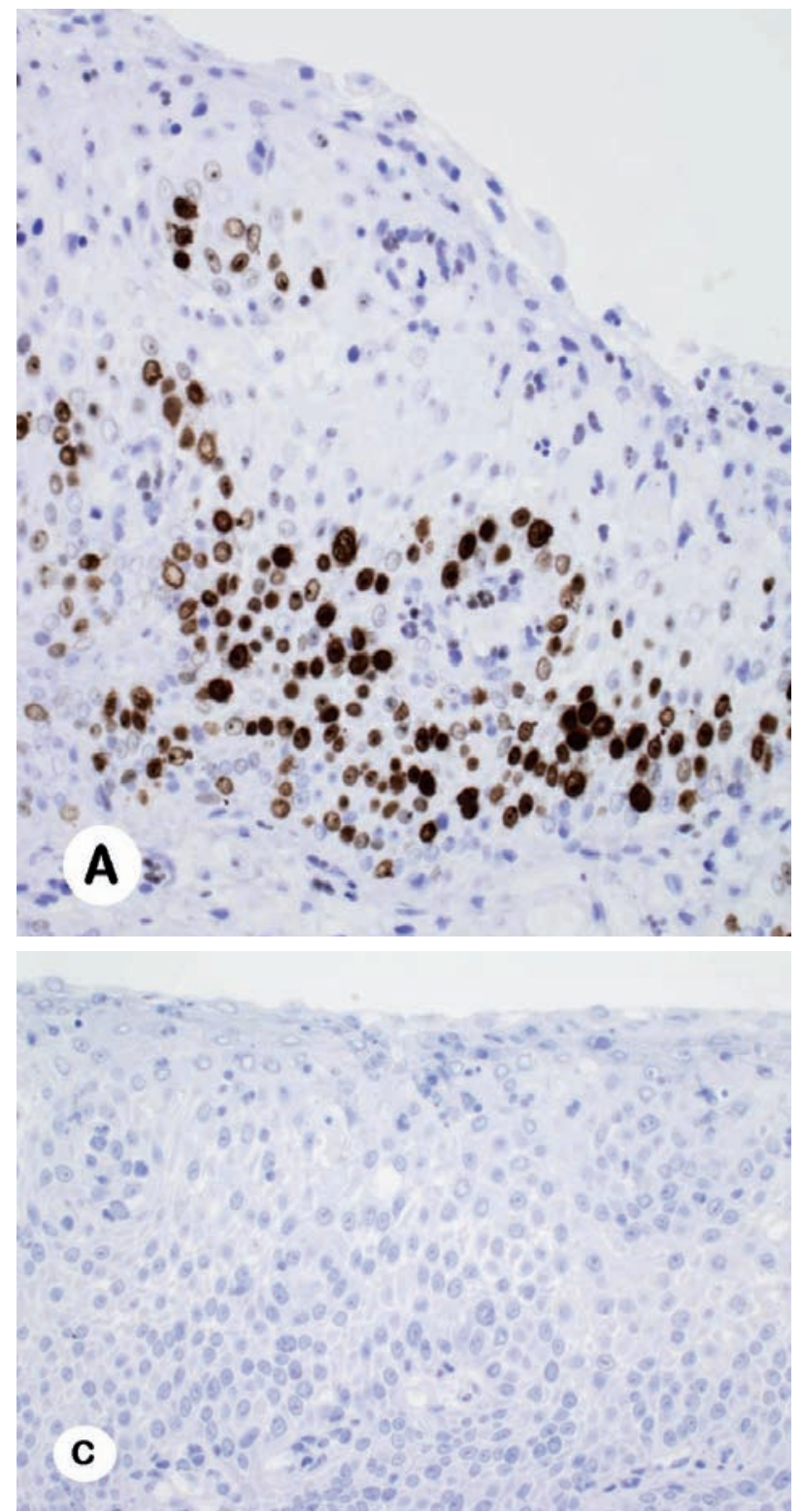

más frecuentemente desarrollado es el adenocarcinoma primario, hecho que posiblemente está relacionado con la alta incidencia de cáncer de colon en la población general, de ahí que la frecuencia de tumores es menor cuando se utiliza intestino delgado. Cuando en estos pacientes se desarrolla un tumor, éste suele ser de tipo urotelial o de la misma extirpe del tumor primario que motivó la cistectomía ${ }^{7,8}$.

En conclusión, la colocistoplastia de aumento es una buena alternativa en los pacientes con una vejiga retráctil tuberculosa, ya que el segmento de intestino grueso se adapta bien a su nueva función

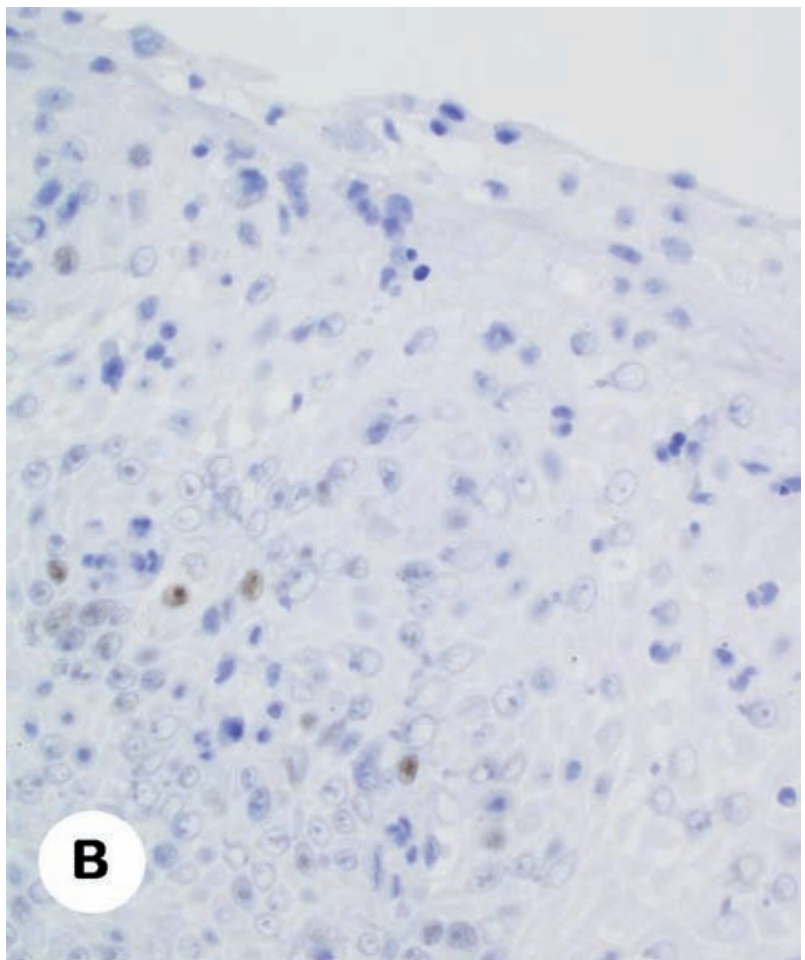

FIGURA 3. Inmunohistoquímica del epitelio de la zona de unión vésico-intestinal, que confirma la ausencia de cambios premalignos. A) Expresión de Ki-67 sólo en el estrato basal y parabasal, propio de un proceso reactivo. B) Débil positividad para p53. C) Ausencia de expresión de citoqueratina 20 en los estratos superficiales.

de reservorio urinario y origina pocas complicaciones. Sin embargo, aunque en nuestro caso observamos la total estabilidad de los epitelios, parece innegable que estos pacientes tienen mayor riesgo de desarrollar una neoplasia vesical y este riesgo aumenta con el paso del tiempo, por lo tanto deben ser seguidos regularmente con cistoscopia y biopsias del remanente vesical, de la zona de unión y del segmento intestinal.

\section{Agradecimientos}

Al Dr. J. Lloreta Trull por sus valiosas aportaciones anatomopatológicas. 


\section{REFERENCIAS}

1. Gil-Vernet JM, Gosalvez R. ¿Iléocystoplastie ou colocystoplastie?. J Urol Med Chir. 1957;63:466-482.

2. Gil-Vernet JM. Colocystoplastie. Technique chirurgicale de la sigmoidocystoplastie latéro-latérale. J Urol Med Chir. 1958;64 (6):301-316.

3. Gil-Vernet JM, Pérez-Trujillo G, Escarpenter J, Gonzalez V, Carreno J, Vergallo E. Resultats obtenus avec la colocystoplastie. J Urol Med Chir. 1960;66(12):775-783.

4. Vajda P, Kaiser L, Magyarlaki T, Farkas A, Vastyan AM, Pinter AB. Histological findings after colocystoplasty and gastroplasty. J Urol. 2002; 168(2): 698-701.

5. Ivil KD, Doak SH, Jenkins SA, Parry EM, Kynaston HG, Parry JM, Stephenson TP. Fluorescence in-situ hybridisation on biopsies from clam iliocystoplasties and on a clam cancer. $\mathrm{Br} \mathrm{J}$ Cancer. 2006;27(6):891-895.
6. Barrington JW, Fraylin L, Fish R, Shelley M, Stephenson TP. Elevated levels of basic fibroblast growth factor in the urine of clam enterocystoplasty. J Urol 1996;155(2):468-470.

7. Barrington JW, Fulford S, Griffths D, Stephenson TP. Tumour in bladder remanent after augmentation enterocystoplasty. J Urol 1997; 157(2):482-486.

8. Ali-El-Dein B, El-Tabey N, Abdel-Latif M, Abdel-Rahim M, ElBahnasawy MS. Late uro-ileal cancer alter incorporation of ileum into the urinary tract. J Urol. 2002; 167(1):84-88.

Correspondencia autor: Dr. A. Arango Toro Servicio de Urología. Hospital del Mar

Passeig Marítim, 25-29 - 08003 Barcelona Tel.: 932483000

E-mail autor: oarango@imas.imim.es

Información artículo: Cartas al director 